\title{
Social Justice in Educational Policy: How do Students Perceive It?
}

\author{
Asal Wahyuni Erlin Mulyadi \\ Department of Public Administration \\ University of Sebelas Maret \\ Surakarta,Indonesia \\ aw.erlinmulyadi@gmai.com
}

\begin{abstract}
Discussing the issue on social justice in educational policy is also important to consider the voice from the students as the beneficiaries. In this study, Focus Group Discussions (FGDs) were performed to a group of senior high school students in public and private schools Yogyakarta city as a data collection technique. The findings highlight some consideration raised by senior high school students on the existing policy on education related to the zone-based school admission and acceptances for all learners. The students perceived a good acceptance for the government inisiatives to have no disrimination in education and achieve education for all while also convey their other consideration especially in term of learners with disabilities and unintended pregnancies.
\end{abstract}

Keywords: educational policy; senior high school; students' perception; social justice

\section{INTRODUCTION}

Public policy, especially in the field of education which is the right for every citizen regardless their circumstances, must accommodate social justice as the fundamental principle. It was stated that the most important priorities in the educational system is providingan an equality of opportunity for all [1]. To achieve such ideal goals is not only under the responsibilities of government but also the entire society, including students. Similarly, it has to involve students for the evaluation of the policy implementation beside the school administrators and implementers. Therefore, exploring how the students perceived on the existing educational policy implemented is important since students are the primary target of the mentioned policy. The purpose of this paper is to discuss the perception of senior high school students about social justice in education in term of school admissions and acceptances for all including for the issues on students with unintended pregnancy.

\section{RESEARCH METHOD}

A qualitative approach with a case study design was performed in this study. The data collection used is a Focus Group Discussions (FGD) for a group of high school students consist of 8-10 students in each group. The students were identified with the help of the teacher; however, it was selected randomly while also considered gender balances and representativeness of all the three classes (grade $X$ to grade XII). An informed consent was given to each student and had it signed by themself or by their parents for those under the age of 17 years old. The study was conducted at four senior high schools in Yogyakarta city during the period of April September 2017. All the data were recorded and transcribed verbatim then were analyzed using an inductive approach

\section{RESULT AND DISCUSSION}

\section{A. Zone-based School Admissions}

The recent requirement applied for school enrollment in Yogyakarta city, that is also implemented in other cities in Indonesia since it is a national regulation, is using a test scores to enroll their intended school. Although in the future this is not desirable because this selection method for school entry is considered to still practice discrimination, at least this is the best option for now.

"The admission for a high school based on the score-exam, in my opinion, is the most objective, there is no any other alternatives aside that option. It is not fair if the selection criteria will be based on, let's say whether the prospective students (the parents) are from a rich family. So, again, the score-based is the best option"

"in my opinion, it is the right of any students to get an education, however there have to be a standart to obtain (=enter a school) to enable the institusion (=school) to keep the good performance of the all learning process"

Moreover, there is a special municipal regulation to support such system in Yogyakarta city intended to minimize the dicrimination and also to develop a qualified school in all regions. In addition to test score result of the academic achievement, this special policy provides an additional score for each students residing in the same sub-district as the subdistrict where the targetted school located and residing in different sub-districts with the additional of 20 and 10 points respectively. This policy is not applied for those from different provinces, meaning that there is no addition of points for them. According to the students, this policy benefits the long future development to provide a good quality school for all learners in all regions.

"the policy from the government to give an additional 10 points to those from different district, like from Bantul to

Corresponding author: Asal Wahyuni Erlin Mulyadi 
Yogya and 20 points to those from the same district like Yogya to Yogya supports the to make all schools favorite and with good quality, which are needed by all prospective students"

The aforementioned zone-based school admission is a new approach implemented in Indonesia under the regulation of the Ministry of Education and Culture number 17 year 2017 about School Admission for New Students in order to achieve the mission of education for all and develop a good quality of learning in all schools. Nonetheless, this policy is still under pro and contra since it also raised some further concerns and other related issues, for example that the competition is not based on the exam score achieved but the distance of their home adress to school which for some is considered unfair.

\section{B. Acceptances for All Learners}

In terms of acceptance of learners with disabilities, they all basically agree that those with unfortunate physical and mental disabilities are able attend to any schools anywhere. Even they expressed that if they have an opportunity to be together with those considered as marginalized or vurverable students since the first time at same school, it will be not a surprise and get them used to such heterogeneous environment as well as raise their respect and sympaty to each other.

However, they also stated that learners with disabilities should consider anythings that may interfere, such as the possibility of being bullied and not getting proper facilities. Therefore, some of them also suggested that due to such conditions, that not all schools provide or ready with facilities to accommodate their special needs, then they are better off going to a special school that may fulfill their substantial facilities.

\begin{abstract}
"We all know that there are SLB (= school for students with special needs), a special school to help them to learn and study like us in "normal" school. They have their own, a school with supported infrastructure to help them"
\end{abstract}

"I think, those students with disabilities must be provided by a school that is only especially for them ... because if they are here (=in a regular school), the may be bullied, not be able to follow the class, and may be annoying to other friend, or possible for them to be disturbed by other students ... so, it's for their own good"

Responding to unwanted pregnancy students as well as to the boy students who make the girl student pregnant, they argued that they should still be given the opportunity to continue their study at the school. This acceptance however, have to be together with a specific requirement such as that the school have to give them an academic punishment and that they all have to be ready to face all the risks both physically and mentally of "the disgrace". If the school has a provision to drop out them from the school, while they also have to seriously try to offer to continue their study but it is still "non- negotiable", then have to accept the school's decision and continue their study in other school or taking a same level of informal education.

"They have their right to continue their education, but have to move to other school. It is a consequence for them who did immoral, as a punishment but not their right to still go to school",

"They have to follow the rule of the school, meaning that if the rule stated that pregnant student will be expelled, so they have to obey and try to find other schools if still want to continue their study"

"Each of us possible to do wrong and bad thing, but it does not mean that we have to lose our right to education. If we got an unintended pregnancy, we still have the right to continue to go to school; we have to fight for that"

Similar to the case of unintended pregnancy, for learners who have a serious illness or chronic disease, the students perceived that they have the same right to education. The students pointed some additional suggestioned include that the disease is not countagious and those learners have to be aware for their health because she/he is the one who knows better about her/his health condition. If possible, according to them it is better to let other friends knows about her/his health condition to enable other friends support a good environment for them.

"If they are sick, and not the contagious illness, in my opinion, they all still can go to school".

"a public school has to accept anyone without any discrimination. All who fulfill the criteria of the admission requirements have the same right, without considering their religion, ethnicity, health and social economis status, or other reasons... No discrimination.... the important things is that they fullfill all the required points for school admission"

In summary, the students perceived that out of the two extreme situation above (disability and unintended pregnancy), there are no any other reasons for any students to go to school. However, they have to fullfill all the general admission requirements.

\section{Racial Issues in Education}

Indonesia has diverse ethnicities and religions, which cannot be denied that in a region/ province there will be a tribe or religion of the majority. This condition is likely to lead to racial issues including in the field of education, which is also unavoidable by the issue of disparity or gap due to vulnerable conditions such as economic status, gender, and disability. Such human rights concerns cause the more complexity issues on social justice [2]. Interestingly, racial issues in education are also found in developed countries such as America. In a 2016, the US GOA reported that "recent literatures shows that 
poor and minority students may not have full access to educational opportunities"[3]. In addition, "racial/ethnic gap between student of color and their teachers has actually increase over the years"[4]. In Malaysia, discrimination because of ethnicity in any field including education was reported increase [5].

Related to this situation, while they understand about the complexity and heteregoneusity of Indonesia, the senior high school students opposed such unfortunate condition in education. They revealed that: "education should not be discriminated for any reasons such us gender, race, ethnicity, or religion. All have the same right. We cannot relate the racial issues to education" This is an important highlight from the students' view that they support the anti discrimination in education. It can be assumed that senior high school students have a high awareness on the important of education for all. "Education is one of the most effective tools for the promotion of equal opportunities for all, irrespective of race, gender, age, disability, sexuality, religion or ethnicity"[6]

\section{The Importance of Equity in Education}

In any topic discussing educational policy, ensuring equity in education including in term of access and quality of learning, is a compulsory. Equity in education guarantees that anyone have access to a high-quality education regardless their circumstances Without it, reaching the ideal goals of education will be much far away. Access to education especially for those vurnerable children, in the future will not only contribute to equity itself but also economic and efficient aspect ${ }^{[7]}$. The students opined that providing a good school especially in term of access, affordability, and quality is a key to solve the inequality in education. They said:

"The development of education through the preparation of quality schools so that each region has a favorite quality school will be a solution to the problem of uneven education and the quality of schools that are lame because there are some schools that are superior".

Social justice in educational policy guarantees the equity for all learners in any aspect such as gender, religion, socio economic status, disabilities, and other circumstances. In facts, to reach such ideal goals will not be easy since every student want to study in a favorite school and affordable in term of cost and distance. Almost every first year of school admission, we can found a crowded students and parents to monitor the admission progress especially in the most favorite targeted school. The higher the status of the school in term of performance and public image, the more competitive for students to enroll which is at the same time may lead to a disparity among the prospective students. In Ghana, the wide disparities in the status of school may also lead some people to "manipulate the process" [8].

\section{CONCLUSION}

Public policy in the field of education, especially in term of school admission has led to social justice although still encountered various discrimination issue which is not easy to be instantly solved. The findings of this study suggest that students perceived a good acceptance for the existing educational policy, while they also expressed a hope for better achievement in the term of social justice for all in the long future.

Racial issues is considered as no reason to be discussed as it is not a concern in Yogyakarta while gender disparities and equal access for person with disabilities still have to be put in a priority agenda. The emphasized voice from the students is about the dream to reach education for all without any discrimination, nonetheless they also expressed that it is not an easy task for both government and society. For a recommendation, further study involving more heterogeneous students from public, private, and religious-based scholl might deeper the findings about the perception of students on social justice in education with various related and recent issues

\section{REFERENCES}

[1] M .M Avc1, M Özbas, "Perceptions of higher education students regarding the equality of opportunity and possibility in education in terms of sociological variables", Educational Research, vol. 4, no. 3, pp. 264-272, 2013.

[2] M.Turhan, "Social justice perceptions of teacher candidates", Educational Research and Review, vol. 5, no. 11, pp. 668-673, 2010.

[3] United States Government Accountability Office (US GOA), "K-12 education: Better use of information could hep agencies identify disparities and adress racial discrimination", April 2016

[4] A.M ,Villegas, K. Strom,T. Lucas, "Closing the racial/ethnic gap between students of color and their teahers: an elusive goals", Equity and Excellence in Education, vol. 45, no. 2, pp. 283-301, 2012.

[5] Pusat KOMAS Malaysia, "Malaysia racial discrimination report 2015", pp. 1-28, 2016.

[6] L.H. Bhandal,, "Fighting racism and promoting equal rights in the field of education", European Network Against Racism, pp. 1-40, 2007.

[7] Schleicher, A, "Equity, excellence and inclusiveness in educatiob: Policy lessons from around the world", OECD, pp. 1-110, 2014.

[8] P.D Ahiatrogah, "Determinants of equity in access to Senior High School Education in the Ghanaian education system". Journal of Educational and Social Research, vol. 3, no. 2, pp. 273-281, 2013. 